\title{
A New Open Loop Approach for Identifying the Initial Rotor Position of a Permanent Magnet Synchronous Motor
}

\author{
Qixin Zhu, ${ }^{1,2}$ Lei Xiong, ${ }^{2}$ Hongli Liu, ${ }^{1}$ Yonghong Zhu, ${ }^{3}$ and Guoping Zhang ${ }^{4}$ \\ ${ }^{1}$ School of Mechanical Engineering, Suzhou University of Science and Technology, Suzhou 215009, China \\ ${ }^{2}$ School of Electrical and Automation Engineering, East China Jiaotong University, Nanchang 330013, China \\ ${ }^{3}$ School of Mechanical and Electronic Engineering, Jingdezhen Ceramic Institute, Jingdezhen 333001, China \\ ${ }^{4}$ Shenzhen Han's Motor Technology Company Limited, Shenzhen 518058, China
}

Correspondence should be addressed to Qixin Zhu; bob21cn@163.com

Received 17 May 2017; Revised 30 July 2017; Accepted 10 October 2017; Published 26 November 2017

Academic Editor: Phillip F. Culverhouse

Copyright (C) 2017 Qixin Zhu et al. This is an open access article distributed under the Creative Commons Attribution License, which permits unrestricted use, distribution, and reproduction in any medium, provided the original work is properly cited.

\begin{abstract}
The precision of initial rotor position detection is critical for the start and running performance of permanent magnet synchronous motor (PMSM). This work describes a new open loop approach for identifying the initial position of a PMSM with an incremental encoder, even when a constant load torque is being applied. By giving a testing current with high frequency to the stator winding, the initial rotor position of a PMSM can be detected with reasonable accuracy. The rotor almost does not move during the process of identification. The FFT algorithms are used to remove the phase bias effects in identification. Our approach is quicker and simpler than the conventional approaches.
\end{abstract}

\section{Introduction}

Permanent magnet synchronous motor (PMSM) has the advantages of compact size, superior power density, high airgap flux density, high torque/inertia ratio, high torque capability, high efficiency, and free maintenance, so it is widely used in high-performance applications such as industrial robot, semiconductor manufacturing equipment, and machine tools [1-5].

The three main PMSM drive strategies are constant frequency ratio control (VVVF) [6, 7], field-oriented control (also called vector control (VC)) $[8,9]$, and direct-torque control (DTC) $[10,11]$. These three drive strategies have their own advantages and disadvantages. With the development of a control theory, various alternative control methods, including switching control, feedback linearization, sliding mode variable structure, neural network control, adaptive control, and fuzzy control, have been used to control PMSM. Most of these control methods are based on the VC and DTC strategies. The PMSM control system exhibits improved performance when combined with these alternative control methods mentioned above [12-17].
All high precision control methods for PMSM need the accurate information of motor position, which is usually acquired by position sensors, such as resolves, encoders, and potentiometers. Among these position sensors, incremental encoders are most widely used because they are relatively cheap and accurate. For a PMSM, maximum torque is generated when the internal magnetic field generated by the motor winding is at a right angle (90 degrees) with respect to the permanent magnet's magnetic field. By controlling the magnitude and direction of the current flowing in the motor windings, the magnetic field generated by them can be made to rotate around the motor axis. The attraction between this rotating field and permanent magnet's magnetic field is what causes motor shaft rotation. Therefore, unless the initial rotor position is known, it is impossible to start a PMSM with maximum torque.

Over the past several decades, several methods for identifying the initial rotor position of a PMSM without the use of commutation signals have been proposed by some authors. Two basic approaches for initial position estimation are pulse signal injection and sinusoidal carrier-signal injection. The pulse signal injection approaches are often 
based on estimating the minimum inductance location [21]. An appropriate voltage pulse width signal is selected and applied to each phase winding of PMSM to partially saturate the stator iron to get the absolute position of the rotor at standstill in [22]. A search algorithm for an optimum voltage vector that uses effective magnetic saturation without rotating the rotor was introduced in [23]. Magnetic axis without polarity was estimated via an indirect flux detection by online reactance measurement and the polarity was detected by finding minimum inductance on the estimated magnetic axis in [24]. Injection of a high frequency, rotating, and/or pulsating sinusoidal carrier-signal has been widely used to estimate initial rotor position of PMSM using either voltage or current injection [25]. In [26], the Taylor series is used to describe the nonlinear magnetic saturation relationship between the current and the flux linkage in the $d$-axis rotor reference frame. The second-order term produces the second harmonic component of the carrier frequency, and the sign of its coefficient identifies the polarity of the rotor magnet being tracked. In [27], the dependence of inductance on rotor position in interior permanent magnet machines is used to estimate the position and the velocity of PMSM. The magnetic axis is identified from the current locus through rotating voltage injection and magnet polarity is detected by finding minimum inductance via square-wave voltage injection for an IPMSM in [28].

However, on the one hand, some works above consider only the case of no-load condition [29] or make the rotor have a big movement [18]. On the other hand, including much of calculus, the identifying algorithms in some works above are very complex $[16,17,21-28,30]$. In this paper, a new open loop approach is proposed to identify initial rotor position of a PMSM with current type driver, which can work well even when a constant load torque is being applied, and the identifying algorithm is very simple and quick. The rotor almost does not move during the process of identification. The FFT algorithms are used to remove the phase bias effects and sine curve fitting is used in our estimation. It does not need any additional circuits and sensors but can provide highly accurate absolute position information quickly.

\section{Problem Formulation}

In a PMSM, the fundamental torque generation equation is given by

$$
\begin{aligned}
T_{e} & =k_{t}\left[i_{a} \cos \left(\theta_{r}\right)+i_{b} \cos \left(\theta_{r}+\frac{2 \pi}{3}\right)\right. \\
& \left.+i_{c} \cos \left(\theta_{r}-\frac{2 \pi}{3}\right)\right],
\end{aligned}
$$

where $T_{e}$ denotes the generated electromagnetic torque, $i_{a}$, $i_{b}$, and $i_{c}$ denote the phase currents, $k_{t}$ is the phase torque constant, and $\theta_{r}$ denotes the rotor electrical angle. The phase currents can be described by the following formulas:

$$
\begin{aligned}
& i_{a}=I_{q} \cos \left(\theta_{r}^{\prime}\right), \\
& i_{b}=I_{q} \cos \left(\theta_{r}^{\prime}+\frac{2 \pi}{3}\right), \\
& i_{c}=I_{q} \cos \left(\theta_{r}^{\prime}-\frac{2 \pi}{3}\right) .
\end{aligned}
$$

Here $I_{q}$ is the torque command current and $\theta_{r}^{\prime}$ is the measured rotor electrical angle by the controller. Substituting (2) into (1),

$$
T_{e}=\left(\frac{3}{2}\right) k_{t} I_{q} \cos \left(\theta_{r}^{\prime}-\theta_{r}\right) .
$$

It is assumed that $\theta_{r} \in[0,2 \pi), \theta_{r}^{\prime} \in[0,2 \pi)$. Obviously, $T_{e}$ gets the maximum value when $\theta_{r}^{\prime}=\theta_{r}$. The electromagnetic torque $T_{e}$ is a positive value when $\left|\theta_{r}^{\prime}-\theta_{r}\right|<\pi / 2, T_{e}$ is zero when $\left|\theta_{r}^{\prime}-\theta_{r}\right|=\pi / 2$, and $T_{e}$ is a negative value when $\mid \theta_{r}^{\prime}-$ $\theta_{r} \mid>\pi / 2$. The dynamic equation of a PMSM is described as follows:

$$
J \ddot{\theta}_{r}+B \dot{\theta}_{r}+T_{L}=T_{e},
$$

where $J, B, T_{L}$ denote moment of inertia, viscous damping coefficient, and load torque, respectively. In real applications, compared to $T_{e}$, the values of $T_{L}$ and $B \dot{\theta}_{r}$ are very small [31]. When the load torque and part of viscous damping coefficient are omitted, (4) can be changed to

$$
J \ddot{\theta}_{r} \approx T_{e} .
$$

From (3) and (5), we can get

$$
\ddot{\theta}_{r} \approx \frac{\left(3 k_{t} I_{q} \cos \left(\theta_{r}^{\prime}-\theta_{r}\right)\right)}{2 J} .
$$

That is to say, the acceleration of the motor is proportional to the torque command current.

\section{Identification Algorithms}

Current type driver means that the command of the driver is the currents, and the current type driver is used in the overwhelming majority of servo system. The structure of the servo system is shown in Figure 1. The digital value from the DSP controller is denoted as DAC; the DAC signal is connected to the input of D/A converter. The output of D/A converter is an analogy value denoting the command of the driver. So the DAC value determines the value of current command.

The identification can be divided into two steps; first step is to use a special high frequency current to excite the mechanical system at six stator flux vectors in open loop state and record the acceleration of the motor. The electrical angle of stator flux vectors is denoted by $\theta_{s}$. The second step is to filter the data with Fast Fourier Transform (FFT) algorithm and identify the initial position of the rotor. 


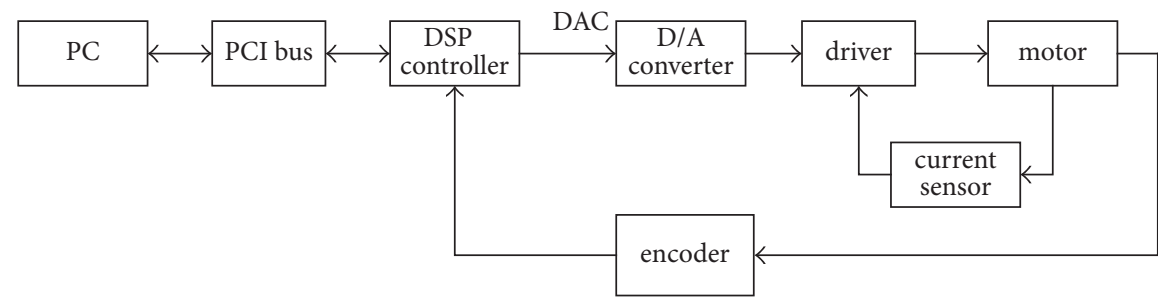

FIgURE 1: The structure of the servo system.

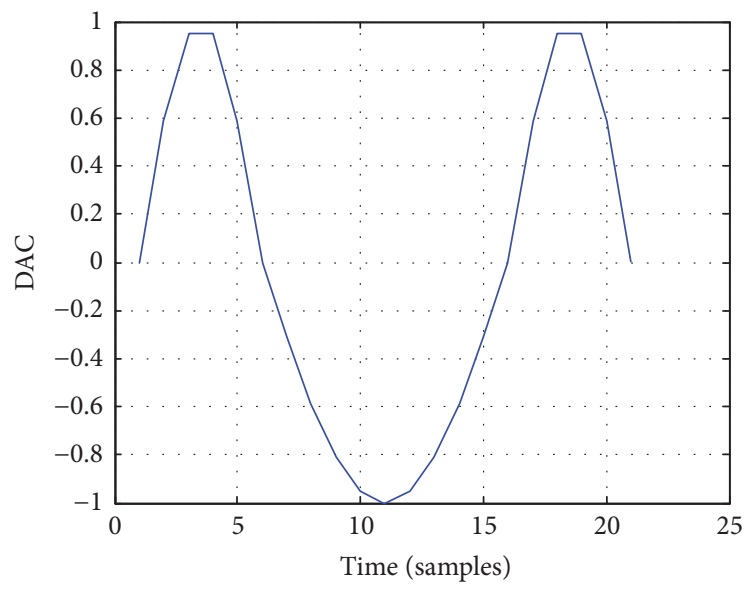

Figure 2: The waveform of exciting DAC.

3.1. The Selection of Exciting Waveform. An approximate sinusoid current waveform is used to excite the mechanical system. On the one hand, we expect that the exciting time is as short as possible to decrease the moving distance of the motor, which needs the frequency of waveform to be as high as possible. On the other hand, we do not expect the frequency of exciting signal to drop into the resonance frequency of the mechanical system, which maybe causes the negative influence on the testing results.

To make the motor have a minimum moving, the exciting signal (DAC signal, it is the torque command current) is designed as in Figure 2. The waveform above the time axis is two sine half-waves with a period $T_{1}$ and the waveform below the time axis is a sine half-wave with a period $T_{2}$, where the two sine waves have the same amplitude and $T_{1}=5 \mathrm{~ms}$, $T_{2}=10 \mathrm{~ms}$. In continuous case, it can be evaluated that the motor will go back to the initial position when the motor is excited by the signal as in Figure 2 where "1" in $y$-axis denotes 500 LSB (Least Significant Bit). The acceleration waveform is similar to the waveform of DAC, so the acceleration, velocity, and the position waveforms of the motor are in Figures 3-5. The benefit of the selected waveform is that the absolute move of the motor is very small when exciting is over.

But, in discrete case, the moving distance of a motor is not zero during one time of exciting when the two sine waves have the same amplitude. In our testing, there are 20 values of DAC in one time of exciting. The ratio of two amplitudes of sinusoid wave is 1.0256 . The coefficient 1.0256 is set to make the total moving distance of the motor equal to zero. If there is

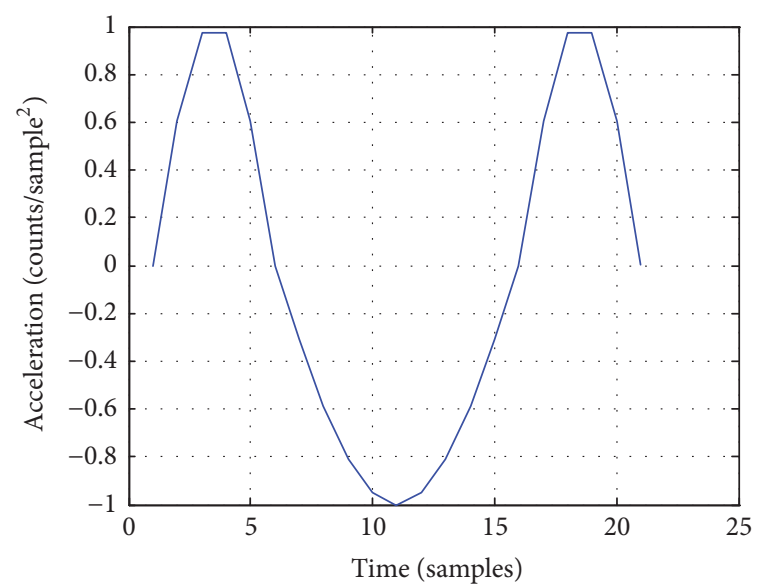

FIGURE 3: The acceleration waveform of the system.

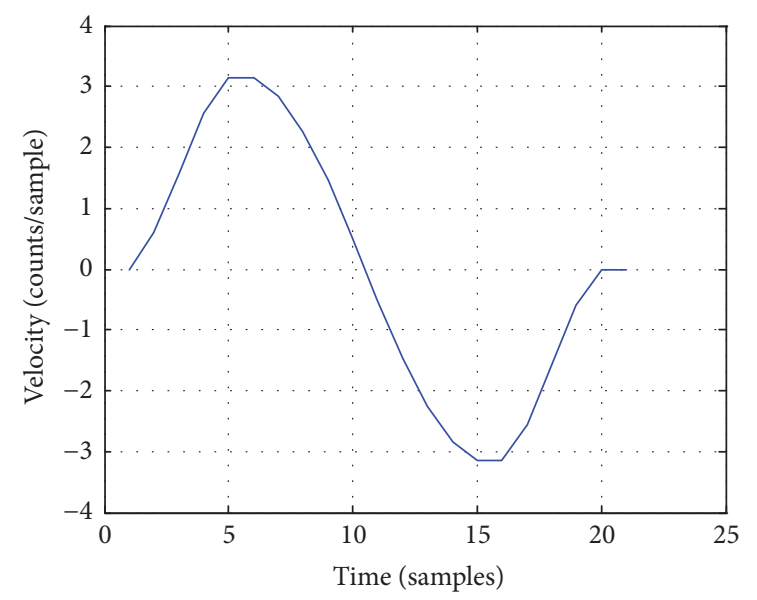

Figure 4: The velocity waveform of PMSM in continuous case.

no coefficient, the waveforms of the velocity and the position are in Figures 6 and 7. That is to say, the motor cannot move back when exciting is over.

3.2. The Effects of the Phase Bias. When the driver of PMSM is well designed and adjusted, the driver has a low phase bias which cannot move the motor at all when the control system is closed. But in some cases the phase bias of the driver is big enough to move the motor when the control system is closed. The big moving of the motor will be negative to the test result of the initial position of the motor. The 


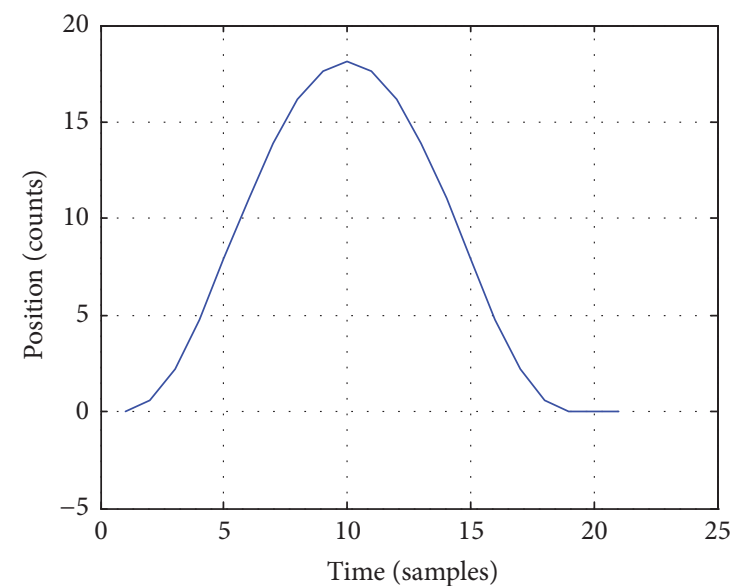

FIgURE 5: The position waveform of PMSM in continuous case.

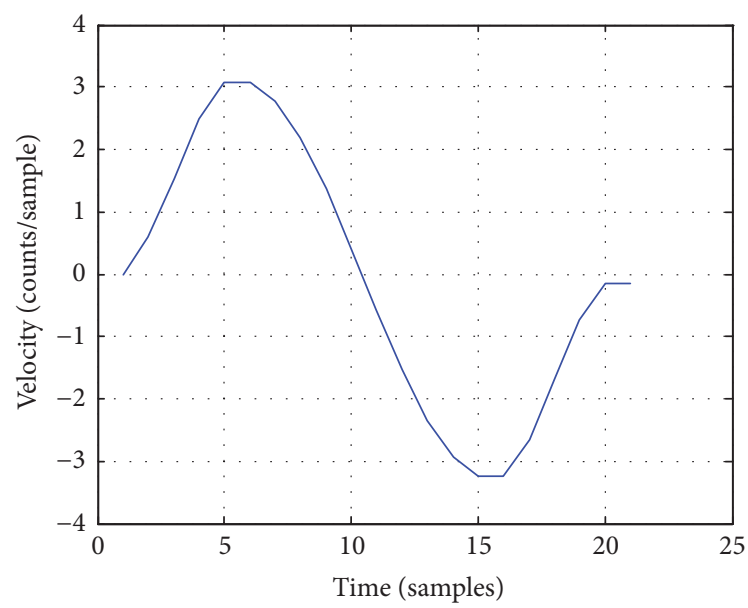

FIGURE 6: The velocity waveform of PMSM in discrete case.

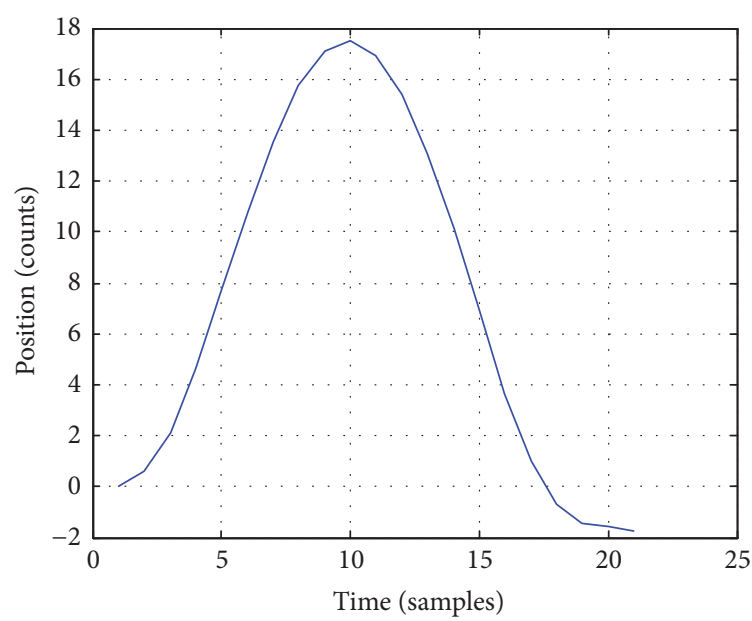

FIGURE 7: The position waveform of PMSM in discrete case.

acceleration waveform of the DDR motor caused by the phase bias is in Figure 8, where the count of a complete cycle is $2,000,000$. This acceleration caused by the phase

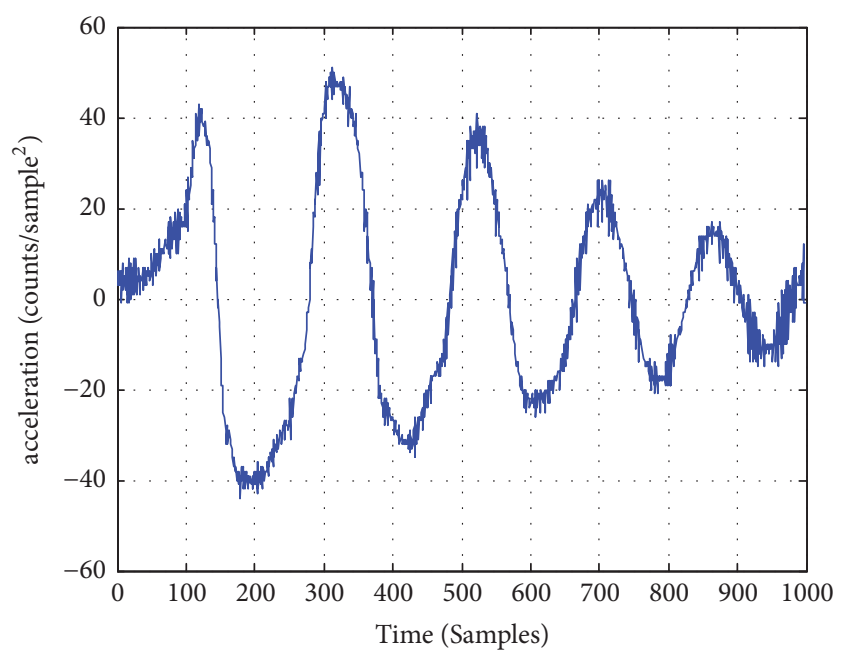

FIGURE 8: The waveform of the acceleration caused by the phase bias.

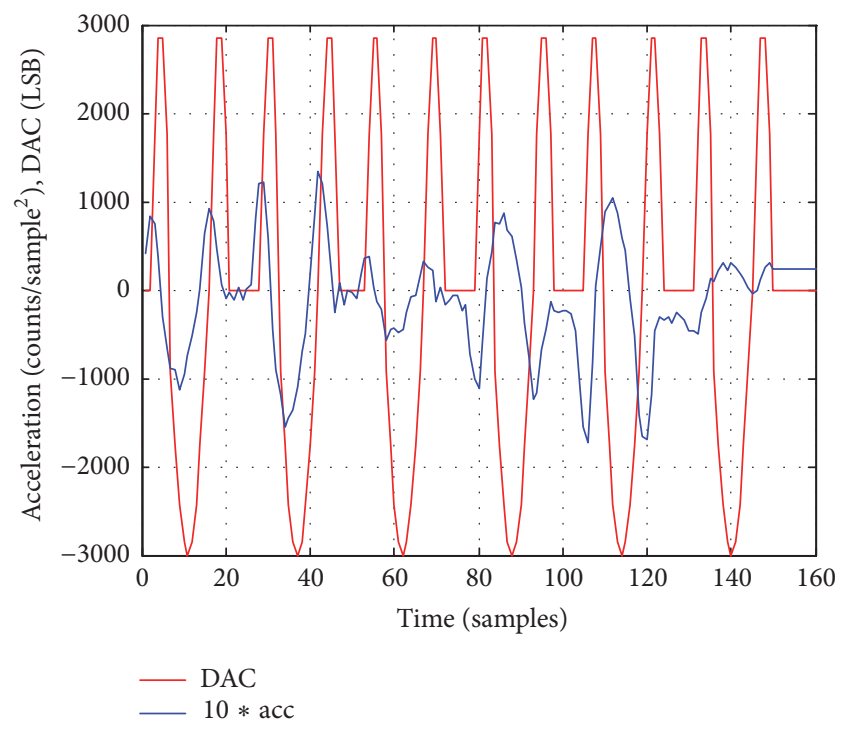

FIGURE 9: The waveforms of the acceleration and DAC.

bias is a damped sinusoidal signal whose frequency is about $20 \mathrm{~Hz}$. When the exciting signal is added to the motor, the acceleration waveform of this motor and the DAC waveform are in Figure 9. At this case, the signal of acceleration includes a low frequency signal which is caused by phase bias of the driver.

3.3. The Identification of Initial Position of PMSM. To get accuracy analyzed result from the signal of the acceleration, the low frequency signal must be eliminated. Using FFT transform, the low frequency signal can be eliminated from the signal of acceleration. From Section 3.1, we know the frequencies of exciting signal are $100 \mathrm{~Hz}$ and $200 \mathrm{~Hz}$. The signal whose frequency is below $60 \mathrm{~Hz}$ should be eliminated. The waveforms of acceleration before FFT transform and 


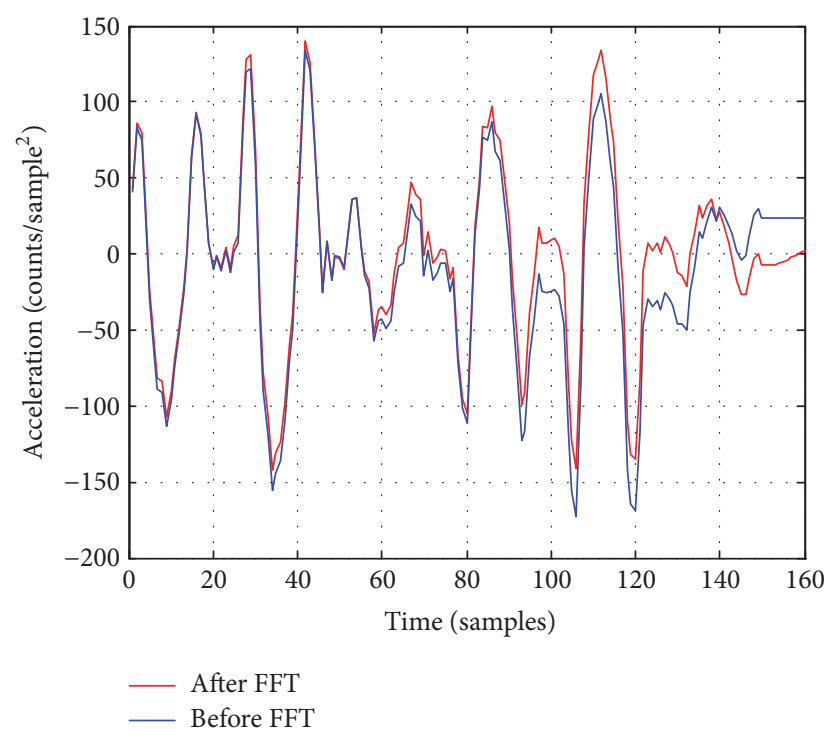

FIGURE 10: The waveforms of the acceleration before FFT and after FFT.

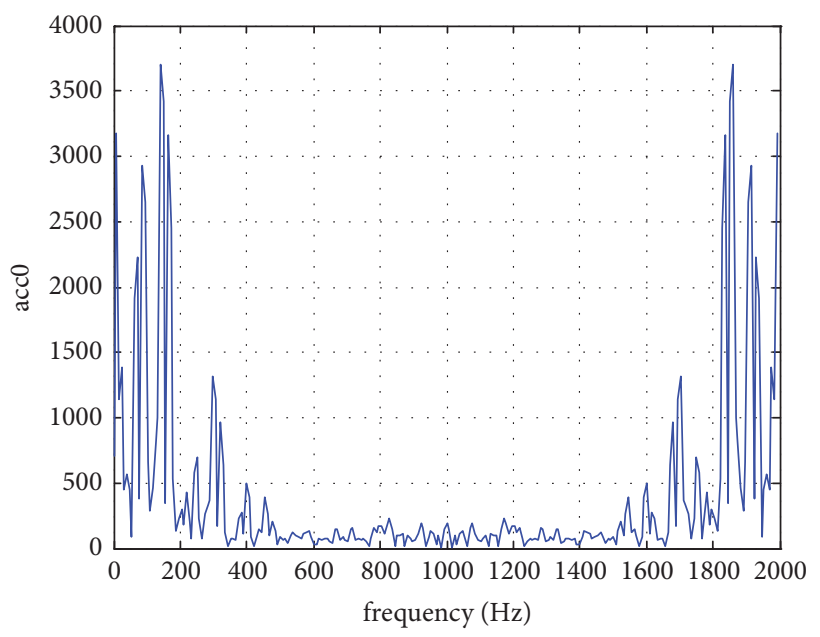

FIGURE 11: The frequency distributed diagram of acceleration before FFT.

after FFT transform are in Figure 10. The frequency distributed diagrams of the acceleration before FFT and after FFT are in Figures 11 and 12. From Figure 12, it is obvious that the amplitude of low frequency signal below $60 \mathrm{~Hz}$ is zero. The parameters of FFT transform are selected as follows. The sampling rate of the system is $2000 \mathrm{~Hz}$, the number of dots in FFT is 256, and the frequency interval between two continuous dots is $2000 / 256=7.8125 \mathrm{~Hz}$.

3.4. The Sine Curve Fitting. Using the values of DAC and acceleration of the motor, we can make a correlative analysis.

$$
b(t)=\int_{t=0}^{T} \mathrm{dac}(t) \times \text { acceleration }(t) d t .
$$

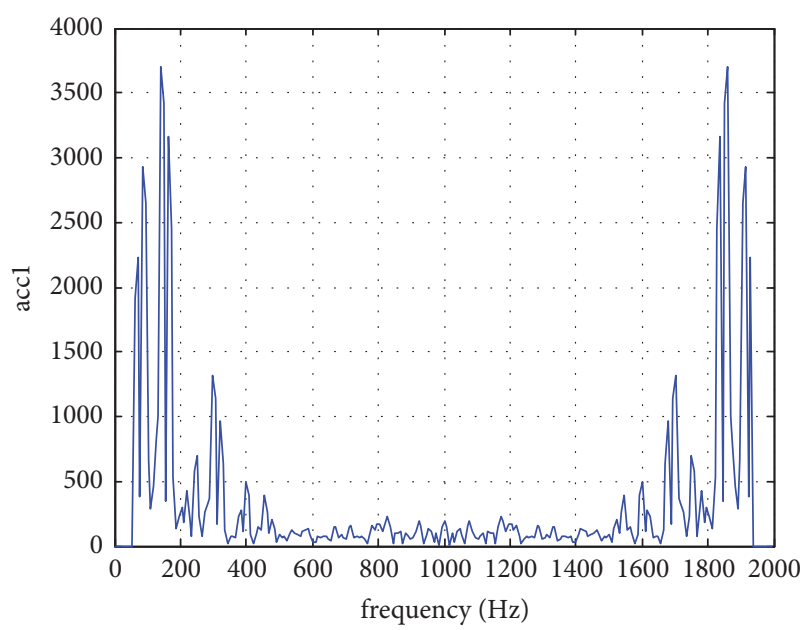

FIGURE 12: The frequency distributed diagram of acceleration after FFT.

Here $T=T_{1}+T_{2} / 2=10 \mathrm{~ms}$; then the values of $b(t)$ should be sine waveform to six stators' flux electrical angle. It is assumed that

$$
b(t)=B \sin \left(\theta_{s}(t)+\phi\right) .
$$

Here $B$ and $\phi$ are the amplitude and the phase of sine waveform. There are 20 values of DAC in completed exciting; and there are 20 values of acceleration in completed exciting.

$$
b(i)=\sum_{j=1}^{20} \operatorname{dac}(j) \times \operatorname{acceleration}(j), \quad i=1,2 \cdots 6 .
$$

In our testing of exciting, six stator flux electrical angles are $\pi / 2,5 \pi / 6,7 \pi / 6,3 \pi / 2,11 \pi / 6$, and $13 \pi / 6$, respectively. If we denote these six angles as $\theta_{s}(i), i=1,2, \cdots 6$, then

$$
\begin{aligned}
& a_{1}=\sum_{j=1}^{6} b(j) \times \sin \left(\theta_{s}(j)\right), \\
& a_{2}=\sum_{j=1}^{6} b(j) \times \cos \left(\theta_{s}(j)\right), \\
& k=\sum_{j=1}^{6}\left(\sin \left(\theta_{s}(j)\right)\right)^{2}=3 .
\end{aligned}
$$

Then

$$
\begin{aligned}
& B=\frac{1}{k} \sqrt{a_{1}^{2}+a_{2}^{2}}=\frac{1}{3} \sqrt{a_{1}^{2}+a_{2}^{2},} \\
& \phi= \begin{cases}\operatorname{arctg} \frac{a_{2}}{a_{1}}, & \text { if } a_{1}>0, \\
\pi+\operatorname{arctg} \frac{a_{2}}{a_{1}}, & \text { if } a_{1}<0, \\
\frac{\pi}{2}, & \text { if } a_{1}=0, a_{2}>0, \\
-\frac{\pi}{2}, & \text { if } a_{1}=0, a_{2}<0 .\end{cases}
\end{aligned}
$$


TABLE 1: Stator electrical angle of exciting and the values of $b(i)$.

\begin{tabular}{ccc}
\hline & $\theta_{s}(i)$ & $b(i)$ \\
\hline 1 & $\pi / 2$ & 31061.1 \\
2 & $5 \pi / 6$ & 99409.5 \\
3 & $7 \pi / 6$ & 95916.1 \\
4 & $3 \pi / 2$ & -2473.3 \\
5 & $11 \pi / 6$ & -99034.8 \\
6 & $13 \pi / 6$ & -97396.6 \\
\hline
\end{tabular}

In our testing, a direct drive rotary (DDR) motor is used. The exciting amplitude of DAC is 500 LSB and the count of a complete cycle is 2,000,000; the six stator electrical angles of exciting and the values of $b(i)$ are in Table 1.

Then

$$
\begin{aligned}
a_{1} & =201522.2, \\
a_{2} & =-275471.4, \\
B & =\frac{1}{k} \sqrt{a_{1}^{2}+a_{2}^{2}}=113771.6, \quad \phi=-0.939206, \\
c(i) & =B \sin \left(\theta_{s}(i)+\varphi\right) \\
& =113771.6 \sin \left(\theta_{s}(i)-0.939206\right), \\
& i=1,2 \cdots 6 .
\end{aligned}
$$

The fitting error is

$$
\frac{\sum_{i=1}^{6}\left|11371.6 \sin \left(\theta_{s}(i)-0.939206\right)-b(i)\right|}{6 B}=6.92 \% .
$$

The initial rotor position of PMSM is $\varphi=-0.9392$.

3.5. The Selection of the Value of DAC. The value of amplitude of DAC in the system is very important in the process of testing. If the value of amplitude of DAC is too small, the signal of acceleration is submerged by the noises and the ratio of the signal and the noise is too small. If the amplitude of DAC is too large, on the one hand it is destructive to the mechanical system, and on the other hand the moving distance of the motor will increase, which is not allowed in many cases. In the testing, we can increase the value of DAC gradually. Normally, the value of fitting error will decline with the increase of the value of DAC. It is OK when the fitting error is below $10 \%$.

3.6. The Testing of a Linear Motor. In another testing, a linear motor is used. A constant load is applied in this linear motor and $m_{\text {load }}=1 \mathrm{~kg}$. The exciting amplitude of DAC is $3000 \mathrm{LSB}$ and the count of a complete cycle is 27,200 . When the exciting signal is added to the motor, the acceleration waveform of this motor and the DAC waveform are in Figure 13. For this linear motor, the phase bias of the motor is not big enough to move the motor when the controlled system is closed. That is to say, there is no low frequency signal caused by phase bias in the waveform of acceleration. As a result, there is no distinct difference between the waveform of the acceleration before

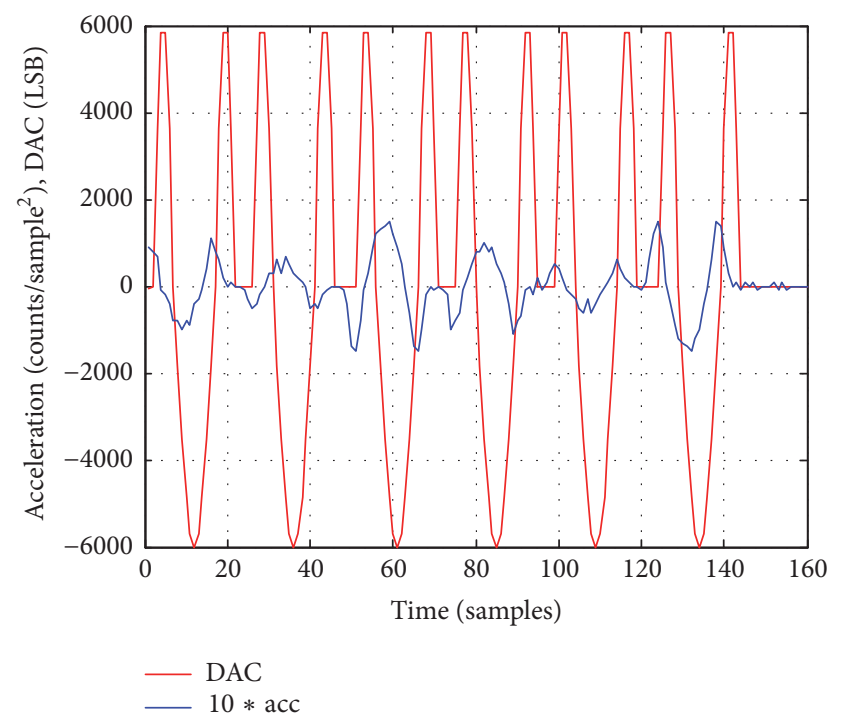

FIGURE 13: The waveforms of the acceleration and DAC.

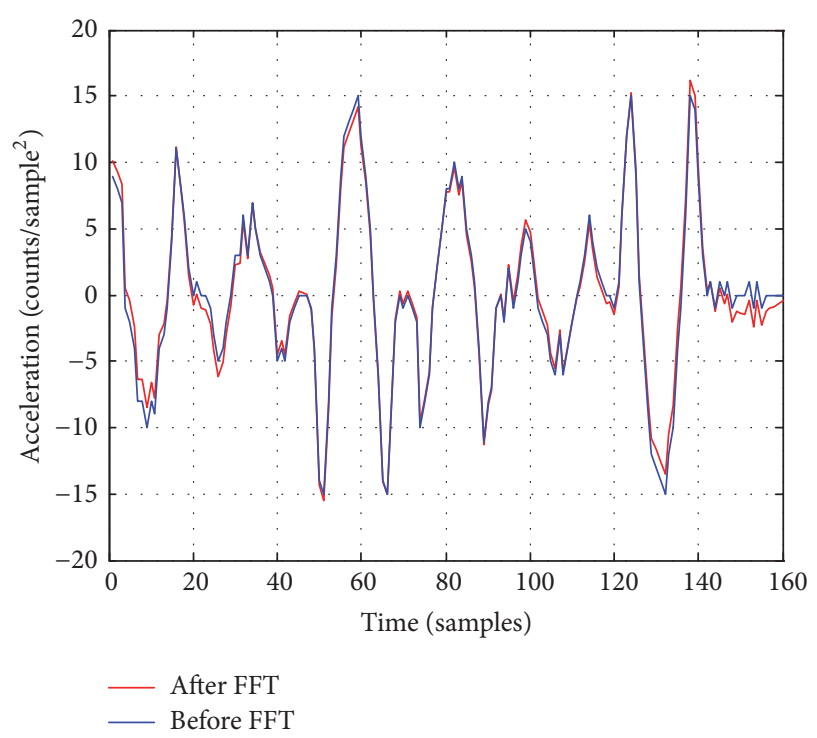

FIGURE 14: The waveforms of the acceleration before FFT and after FFT.

FFT and that after FFT (Figure 14). Using the same process presented above, the initial rotor position of this linear motor is $\varphi=0.9717$ and the fitting error is $6.79 \%$.

3.7. The Estimation Error and Identification Time. The estimation error of this method is less than 8 electrical degrees and the total time taken for identification is less than $130 \mathrm{~ms}$. The comparison between this method and other methods is illustrated in Table 2. The identification times of the methods in $[19,20]$ are not given.

\section{Conclusions}

A novel approach to estimating the initial position of A PMSM is presented in this paper. The major merits of our 
TABLE 2: The comparison between this method and other methods.

\begin{tabular}{lcc}
\hline & The estimation error & Identification time \\
\hline Method in [18] & 5 electrical degrees & $6 \mathrm{~s}$ \\
Method in [19] & 6 electrical degrees & - \\
Method in [20] & 7.4 electrical degrees & - \\
Method in this paper & 8 electrical degrees & $130 \mathrm{~ms}$ \\
\hline
\end{tabular}

identification algorithm are very simple and fast and the rotor almost does not move. It can identify the initial position of a PMSM with an incremental encoder more reliably. The more accurate closed loop identification algorithms will be investigated in the future.

\section{Conflicts of Interest}

The authors declare that there are no conflicts of interest regarding the publication of this paper.

\section{Acknowledgments}

This work was partly supported by National Natural Science Foundation of China under Grants 51375323 and 61563022, Major Program of Natural Science Foundation of Jiangxi Province, China, under Grant 20152ACB20009, Scientific Research Foundation of Suzhou University of Science and Technology under Grant XKZ201409, Foundation of Jiangsu Key Laboratory of Intelligent Building Energy Efficiency, and Qing Lan Project of Jiangsu Province, China.

\section{References}

[1] Z. Wang, J. R. Luo, and C. Jong, "Robust speed estimation of sensorless PMSM based on neural networks adaptive observer," International Journal of Robotics and Automation, vol. 31, no. 5, pp. 428-438, 2016.

[2] S. Wen, G. Qin, B. Zhang et al., "The study of model predictive control algorithm based on the force/position control scheme of the 5-DOF redundant actuation parallel robot," Robotics and Autonomous Systems, vol. 79, pp. 12-25, 2016.

[3] Y.-H. Weng, C.-H. Chen, and C.-T. Sun, "Toward the humanrobot co-existence society: on safety intelligence for next generation robots," International Journal of Social Robotics, vol. 1, no. 4, pp. 267-282, 2009.

[4] F. F. M. EI-Sousy, "Adaptive hybrid control system using a recurrent RBFN-based self-evolving fuzzy-neural-network for PMSM servo drives," Applied Soft Computing, vol. 2014, no. 21, pp. 509-532, 2014.

[5] K.-Y. Chen, J.-S. Hu, C.-H. Tang, and T.-Y. Shen, "A novel switching strategy for FOC motor drive using multi-dimensional feedback quantization," Control Engineering Practice, vol. 20, no. 2, pp. 196-204, 2012.

[6] H. Yang, J. Yang, and B. Xu, "Computational simulation and experimental research on speed control of VVVF hydraulic elevator," Control Engineering Practice, vol. 12, no. 5, pp. 563568, 2012.

[7] B. Xu, J. Yang, and H. Yang, "Comparison of energy-saving on the speed control of the VVVF hydraulic elevator with and without the pressure accumulator," Mechatronics, vol. 15, no. 10, pp. 1159-1174, 2005.
[8] K. Gulez, A. A. Adam, I. E. Buzcu, and H. Pastaci, "Using passive filters to minimize torque pulsations and noises in surface PMSM derived field oriented control," Simulation Modelling Practice and Theory, vol. 15, no. 8, pp. 989-1001, 2007.

[9] R. G. Shriwastava, "Sensorless field-oriented control of PMSM drive system for automotive application," International Journal of Electric and Hybrid Vehicles, vol. 8, no. 3, pp. 213-224, 2016.

[10] A. A. Hassan and E. G. Shehata, "High performance direct torque control schemes for an IPMSM drive," Electric Power Systems Research, vol. 89, pp. 171-182, 2012.

[11] Y. Inoue, S. Morimoto, and M. Sanada, "Examination and linearization of torque control system for direct torque controlled IPMSM," IEEE Transactions on Industry Applications, vol. 46, no. 1, pp. 159-166, 2010.

[12] A. D. Alexandrou, N. K. Adamopoulos, and A. G. Kladas, "Development of a constant switching frequency deadbeat predictive control technique for field-oriented synchronous permanent-magnet motor drive," IEEE Transactions on Industrial Electronics, vol. 63, no. 8, pp. 5167-5175, 2016.

[13] M. N. Uddin, H. Zou, and F. Azevedo, "Online loss-minimization-based adaptive flux observer for direct torque and flux control of PMSM drive," IEEE Transactions on Industry Applications, vol. 52, no. 1, pp. 425-431, 2016.

[14] H. A. Mohamed, A. Z. Sherif, A. M. Osamai et al., "current trajectory for field weakening control of PMSM in wide speed range," International Review of Electrical Engineering, vol. 11, no. 1, pp. 45-54, 2016.

[15] W.-C. Wang, T.-H. Liu, and Y. Syaifudin, "Model Predictive Controller for a Micro-PMSM-Based Five-Finger Control System," IEEE Transactions on Industrial Electronics, vol. 63, no. 6, pp. 3666-3676, 2016.

[16] T. Turker, U. Buyukkeles, and A. F. Bakan, "A Robust Predictive Current Controller for PMSM Drives," IEEE Transactions on Industrial Electronics, vol. 63, no. 6, pp. 3906-3914, 2016.

[17] H. Li, H. Yao, S. Hou, and P. Wang, "Current sensor fault diagnosis and adaptive fault-tolerant control of PMSM drive system based on differential algebraic method," International Journal of Applied Electromagnetics and Mechanics, vol. 53, no. 3, pp. 551565,2017

[18] D.-H. Jung and I.-J. Ha, "An efficient method for identifying the initial position of a PMSM with an incremental encoder," IEEE Transactions on Industrial Electronics, vol. 45, no. 4, pp. 682685, 1998.

[19] S. Ichikawa, M. Tomita, S. Doki, and S. Okuma, "Sensorless control of permanent-magnet synchronous motors using online parameter identification based on system identification theory," IEEE Transactions on Industrial Electronics, vol. 53, no. 2, pp. 363-372, 2006.

[20] M. Boussak, "Sensorless speed control of nonsalient permanent-magnet synchronous motor using rotor-position-tracking PI controller," IEEE Transactions on power Electronics, vol. 20, no. 6, pp. 1413-1422, 2005.

[21] H. Kim, K.-K. Huh, R. D. Lorenz, and T. M. Jahns, "A novel method for initial rotor position estimation for IPM synchronous machine drives," IEEE Transactions on Industry Applications, vol. 40, no. 5, pp. 1369-1378, 2004.

[22] K. Takeshita and N. Matsui, "Senserless control and initial position estimation for surface permant magnet synchronous motor," in Proceedings of the IEEE-IAS Annual Meeting, pp. 2592-2597, 2001.

[23] S. Nakashima, Y. Inagaki, and I. Miki, "Sensorless initial rotor position estimation of surface permanent-magnet synchronous 
motor," IEEE Transactions on Industry Applications, vol. 36, no. 6, pp. 1598-1603, 2000.

[24] M. Schroedl, "Sensorless control of AC machines at low speed and standstill based on the "INFORM" method," in Proceedings of IEEE-IAS Annual Meeting, pp. 270-277, San Diego, CA, USA.

[25] P. L. Jansen, M. Corley, and R. D. Lorenz, "Flux, position and velocity estimation in AC machines at zero and low speed via tracking of high frequency saliencies," in Proceedings of EPE Conference, pp. 154-160, 1995.

[26] Y. Jeong, R. D. Lorenz, T. M. Jahns, and S. Sul, "Initial rotor position estimation of an interior permanent magnet synchronous machine using carrier-frequency injection methods," in Proceedings of the IEEE International Electric Machines and Drives Conference (IEMDC '03), pp. 1218-1223, June 2003.

[27] M. J. Corley and R. D. Lorenz, "Rotor position and velocity estimation for a salient-pole permanent magnet synchronous machine at standstill and high speeds," IEEE Transactions on Industry Applications, vol. 34, no. 4, pp. 784-789, 1998.

[28] S. Kondo, A. Takahashi, and T. Nishida, "Armature current locus based estimation method of rotor position of permanent magnet synchronous motor without mechanical sensor," in Proceedings of the IEEE-IAS Annual Meeting, pp. 55-60, October 1995.

[29] J. S. Kim and S. S. Sul, "New stand-still position detection strategy for PMSM drive without rotational transducers," in Proceedings of the APEC, pp. 363-369, February 1994.

[30] P. B. Schmidt, M. L. Gaspery, G. Ray et al., "Initial rotor angle detection of a nonsalient pole permanent synchronous machine," in Proceedings of the IEEE-IAS Annual Meeting, pp. 807814, 2001.

[31] G. Ellis, Control system design guide, Boston: Academic Press, 2000. 


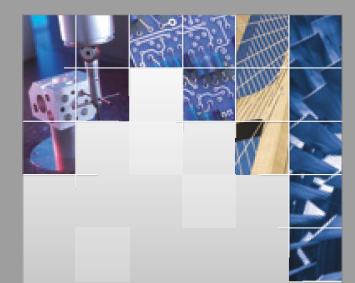

\section{Enfincering}
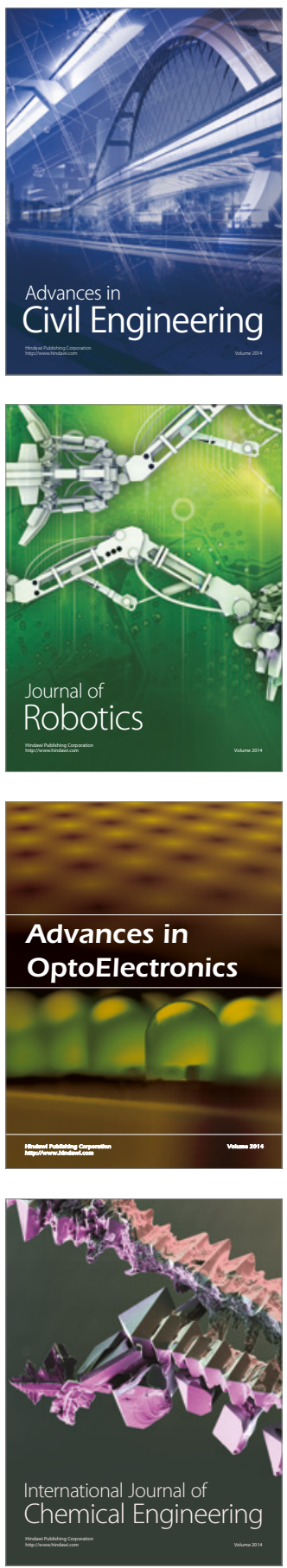

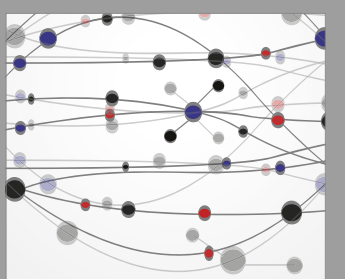

The Scientific World Journal

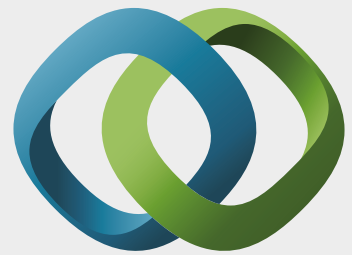

\section{Hindawi}

Submit your manuscripts at

https://www.hindawi.com
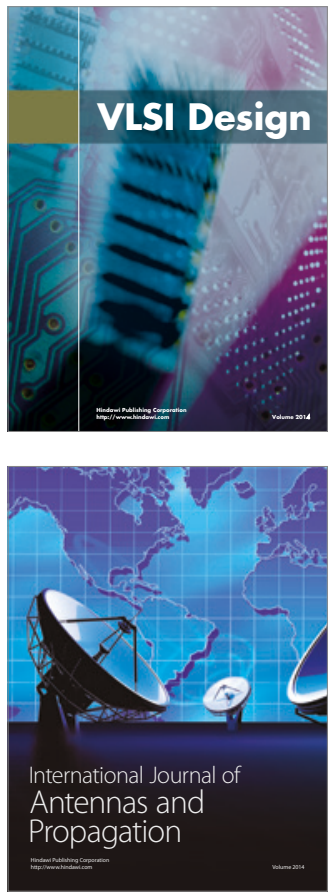

\section{Rotating}

Machinery
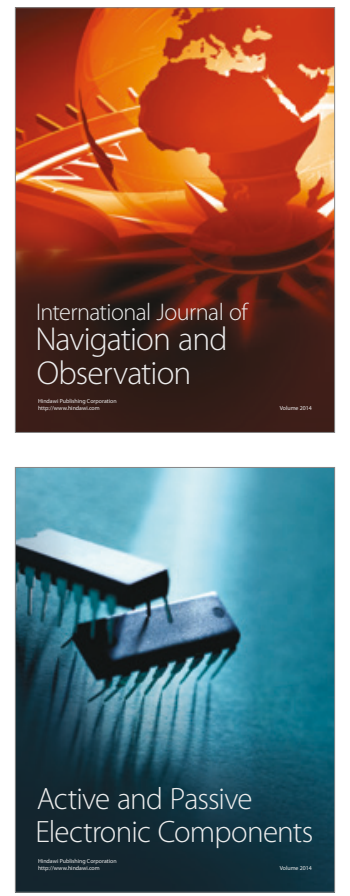
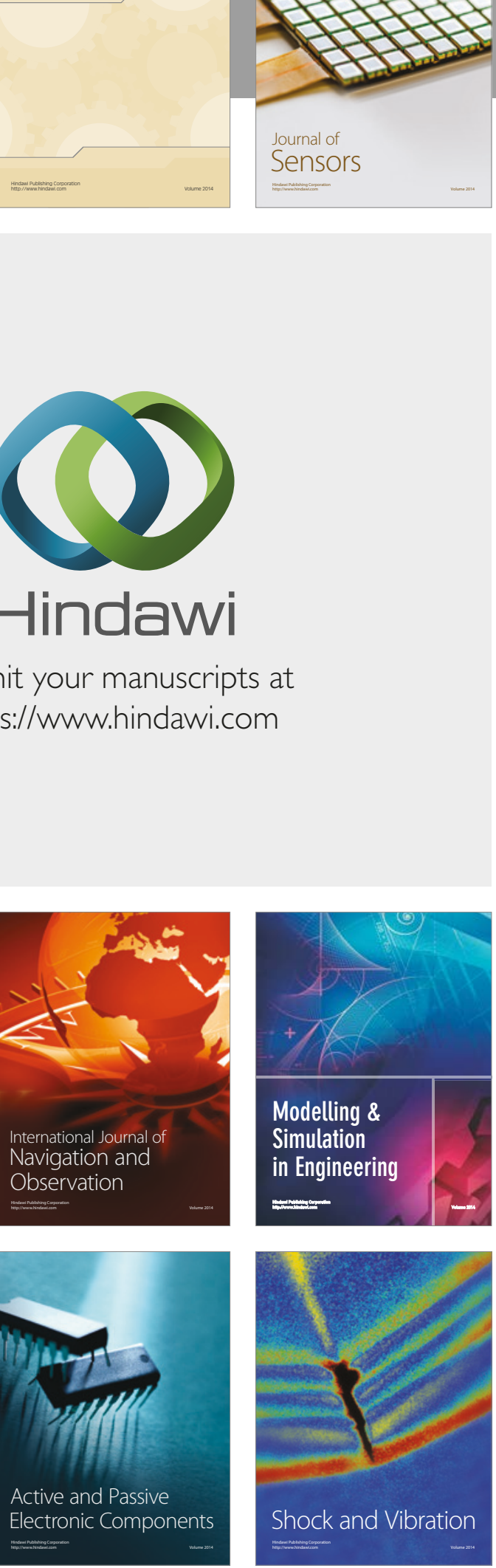
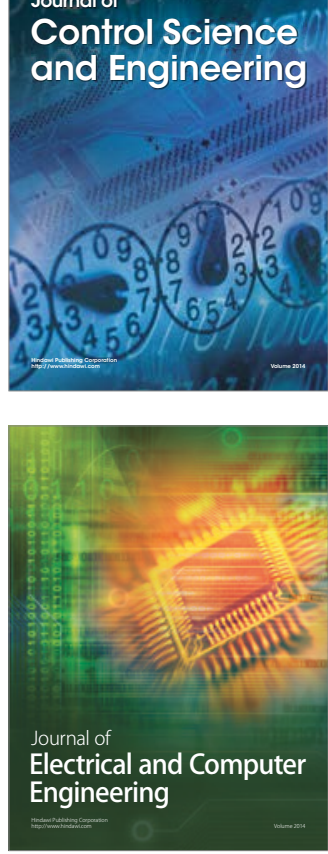

Distributed

Journal of

Control Science

and Engineering
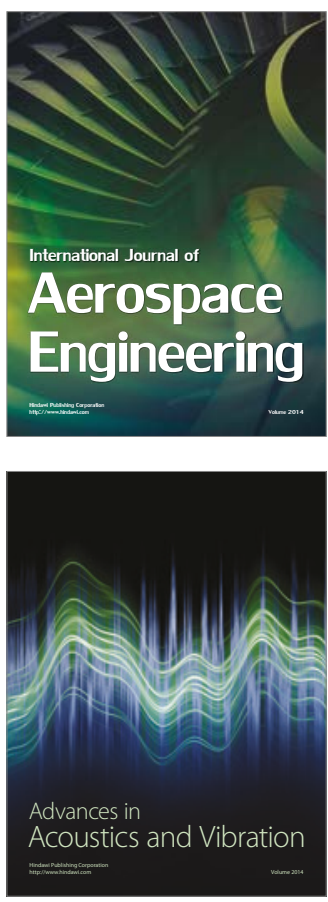

Sensor Networks 